October. A full account of the species will be published elsewhere.

University College, Hull. Oct. 19.

1 Messikommer, E., and V'scher, W., "Ueber eine neue flutende Heterokonte, Chlorosaccus ulvaceus",'Ber. Schweiz. Bot. Ges., 56 (1946).

\section{Fluorochromy as an Aid in the Resolution of the Specific Granules of the Islets of Langerhans}

Visualizatron of individual granules in beta-cells of the islets of Langerhans is particularly difficult in many species, including man. Aside from electron microscopy, few techniques provide sufficient resolution to detect variations in the size or shape of individual granules owing to their minute size. Phase microscopy of stained specimens has proved satis. factory for observing extreme. deviations from the normal $^{1}$; but variations of less magnitude are difficult to assess. Strongly fluorescent granules illuminated by long ultra-violet rays $(\lambda 300-400 \mathrm{~m} \mu)$ act as selfluminous sources of visible light located within the specimen, and this permits use of the maximum aperture of apochromatic oil-immersion objectives. As the autofluorescence of islet cell granules is weak ${ }^{2}$, their fluorescence must be intensified for adequate results. Various fluorochrome dyes were tried for this purpose and some yielded results which appear definitely superior to those obtained by either conventional or phase microscopy. The methods evolved are briefly outlined here, as most reports concerning fluorescence microscopy of the pancreas ${ }^{2-4}$ make little reference to the use of fluorochrome dyes.

Paraffin sections $(3 \mu)$ of Bouin-fixed pancreatic tissue obtained from normal Wistar albino rats were washed in tap water until all visible traces of yellow were removed. Thorough washing is necessary in order to remove picric salts, for if these remain in the sections fluorescence is quenched. A number of fluorochrome dyes were tried, including primuline, thioflavine $S$, acridine yellow ( $h 107)$, acriflavine, coriphosphine, auramine $O$ (all obtained from Edward Gurr, Ltd., London) and rhodamine $B$ (749, Hopkin and Williams, Ltd., London). Sections were immersed for 2-4 min. in filtrates of saturated aqueous solutions of the various dyes, either alone or in combination. After a brief rinse in tap water, slides were blotted, rapidly dehydrated by a few dips in absolute ethyl alcohol, and cleared in xylol. Preliminary trials with a variety of mounting media indicated that the greater the difference between the refractive index of the granules and that of the mounting media the more intense the fluorescence. Xylol was found very satisfactory for temporary mounts (refractive index 1.494). The light source was a 250 -watt highpressure mercury lamp (British Thomson-Houston) with all appreciable visible light removed by a thick $(5 \mathrm{~mm}$.) filter of Wood's glass. A quartz reflecting prism and a quartz condenser were employed, although others of glass will serve almost as well. A Cooke apochromatic oil-immersion objective (N.A. 1.32 ) was used in combination with a $10 \times$ ocular and a green glass eyepiece filter to eliminate the ultra-violet background. Shillaber's immersion oil was employed because of its low fluorescence.

The best results were obtained with sections stained with acriflavine, although those treated with either primuline or thioflavine $S$ were almost equally satisfactory. These imparted an intense (yellowish)

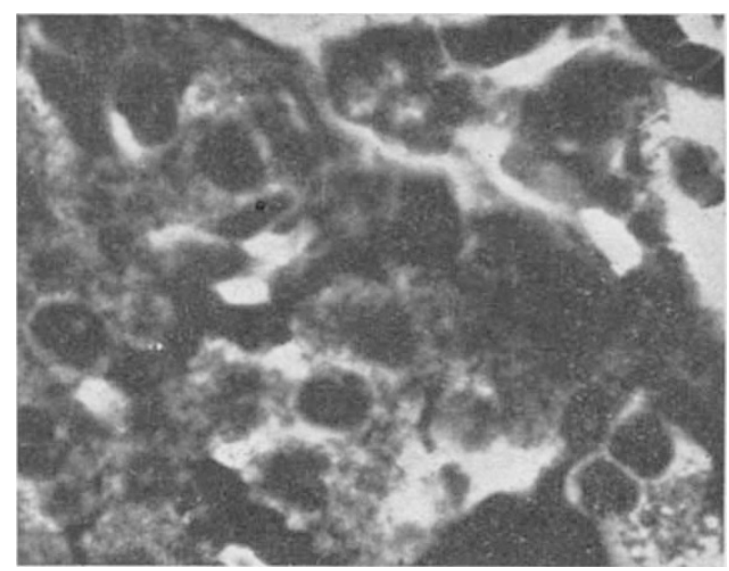

Pancreas stained with acriflavine illuminated by long ultraviolet rays. Details of fixation and staining are given in text. The unstained nuclej appear as oval black areas. The granules in both acinar and islet cells appear white against a black background. of an alpha-cell just to the left of this appears almost entirely of an alpha-cell just to the left of this appears almost entirely
white, for its granules are crowded closely together. The rewhite, for its granules are crowded closely together. The remainder of the islet, which nearly fils the entire feld, is made up
of beta-cells. Their granules appear as small white bodies. Final magnification, $1,100 \times$

fluorescence to the granules in islet cells, as illustrated in the accompanying photomicrograph. After initial treatment with any of these fluorochromes, if the sections are counterstained with rhodamine $B$, the islets are sharply differentiated from surrounding acinar cells, for the latter emit a strong orange fluorescence from their basal portions. Tinctorial differentiation of alpha- and beta-cells was not achieved with any of the fluorescent dyes tried; but characteristics of individual granules are so clearly resolved that cell-types may be identified by the size and number of their granules. In these sections, the granules appear larger than when stained by more conventional methods. Adsorption of dye on the surface of the granule may be responsible, at least in part, for this phenomenon. Alpha-cells appear brighter than beta-cells, for granules in the former are more numerous and closely packed. Betacell granules can be so clearly resolved that it is quite possible to observe distinctly their individual size and shape in many instances. This should prove of distinct value in studies of the experimental histology and pathology of the islets of Langerhans.

The possibilities of fluorochromy as an aid in visualization of the details of very small structures do not seem to have been fully explored. It is possible that applications of this technique to other organs might be of assistance to cytologists in resolving minute bodies.

The techniques described were developed in the Department of Human Anatomy, University Museum, Oxford, during study leave from the University of Toronto. Thanks are due to Dr. Robert Barer for providing facilities and for his continuous advice and encouragement.

Banting and Best

W. Stanley Hartroft

Department of Medical Research, University of Toronto. Sept. 1.

1 Hartroft, W. Stanley, J. Clin. Endocrin., 10, 828 (1950).

'Sjöstrand, F., "Uber die Eigenfuoreszenz tierischer Gewebe mit besonderer Berücksichtigung der Saugetierniere" (Stockholm : P. A. Norstedt and Söner, 1944)

3 Grafflin, A. L., Anat. Rec., 78, 207 (1940)

4 Ellinger, P., Biol. Rev., 15, 323 (1940). 